\title{
BMJ Open Patient and public priorities for breast cancer research: a qualitative study in the UK
}

\begin{abstract}
George Boundouki (D) , ${ }^{1}$ Rebecca Wilson, ${ }^{1}$ Paula Duxbury, ${ }^{1}$ Julia Henderson, ${ }^{2}$ Laura Ballance, ${ }^{1}$ Julie Wray, ${ }^{3}$ Vivienne Appanah, ${ }^{3}$ Ibrahim Ibrahim, ${ }^{1}$ James Harvey, ${ }^{1}$ Cliona Clare Kirwan (10, ,1,4 the Northwest Breast Research Collaborative
\end{abstract}

To cite: Boundouki G, Wilson R, Duxbury P, et al. Patient and public priorities for breast cancer research: a qualitative study in the UK. BMJ Open 2021;11:e036072. doi:10.1136/ bmjopen-2019-036072

- Prepublication history for this paper is available online. To view these files, please visit the journal online (http://dx.doi org/10.1136/bmjopen-2019036072).

Received 28 November 2019 Revised 18 June 2020 Accepted 04 August 2020

\section{Check for updates}

\section{(c) Author(s) (or their} employer(s)) 2021. Re-use permitted under CC BY-NC. No commercial re-use. See rights and permissions. Published by BMJ.

${ }^{1}$ The Nightingale Breast Cancer Unit, Wythenshawe Hospital, Manchester University NHS Foundation Trust, Manchester, UK

${ }^{2}$ Royal Liverpool University

Hospital, Liverpool, UK

${ }^{3}$ Independent Patient

Representative, Manchester, UK ${ }^{4}$ Division of Cancer Sciences, The University of Manchester, Manchester, UK

\section{Correspondence to} Professor Cliona Clare Kirwan; cliona.kirwan@manchester. ac.uk

\section{ABSTRACT}

Objective Internationally recognised specialist breast cancer scientists, clinicians and healthcare professionals have published breast cancer research gaps that are informing research funding priorities in the UK and worldwide. We aimed to determine the breast cancer research priorities of the public to compare with those identified by clinicians and scientists. Design We conducted a qualitative study and thematic analysis using 'listening events' where patients with breast cancer and public representatives used a patient's breast cancer journey to identify research themes.

Participants and setting Female participants were recruited from attendees at participating hospitals and support groups in the northwest of England, including patients, their family and friends as well as staff at a local retail centre.

Intervention A framework approach was used to analyse transcribed discussions until thematic saturation was reached. Main outcome measures Breast cancer research priorities were identified from participant discussions and compared with the published gaps identified by scientists and healthcare professionals.

Results Thematic saturation was reached after 27 female participants participated in listening events. Our participants consistently focused on improved methods of dissemination of information and improving education on the signs and symptoms of breast cancer. This was not highlighted by scientists or healthcare professionals. There was strong emphasis on quality of life-related issues such as side effects of treatment. There was some agreement between the priorities deduced by our study and those of the professionals in the areas of screening, prevention and breast reconstruction. Conclusion Our study identified some research themes that were not identified by scientists and healthcare professionals in two earlier landmark studies. This highlights the importance of including patients and public representatives when setting research priorities. The results should be used to guide investigators when planning future studies and for funding bodies in allocating resources for future projects.

\section{INTRODUCTION}

Breast cancer is the most common female cancer with an annual incidence of more than 50000 in the $\mathrm{UK}^{12}$ and more than 2 million worldwide. ${ }^{3}$ Advances in diagnostics and treatment (surgical and non-surgical) as a result of research have led to a decline in
Strengths and limitations of this study

- Lay members of the public involved in study design and data analysis as part of steering committee.

- Study team included research psychologist trained in conducting and analysing qualitative research.

- Study participants included patients and members of the public without personal or family experience of breast cancer.

Relatively small number of participants.

the mortality rate, particularly in advanced economies. ${ }^{4}$ Despite this, in the UK, fewer than one in seven patients are recruited into a clinical trial. ${ }^{5}$ Traditionally, research ideas are generated by clinical or academic researchers based on areas of perceived need and are judged on scientific merit rather than on relevance and importance of outcomes to potential participants or patients. ${ }^{6}$ More recently, the importance of patient and public involvement (PPI) in study design and management has been recognised. The benefits include improved relevance to patients, enabling wide participation and raising awareness of research. ${ }^{7-9}$ In 1996 , the National Institute for Health Research (NIHR) set up the INVOLVE initiative to 'support public involvement in ..... research, ${ }^{10}$ and in 2009, Independent Cancer Patients' Voice (a nonprofit, patient led organisation) was set up to provide researchers with access to patients and carers who have direct experience of cancer to assist in the setting up, conduct and dissemination of medical research.

In 2013, Breast Cancer Campaign (BCC) funded a gap analysis to determine areas of research need in breast cancer. This involved over 100 internationally recognised, specialist breast cancer scientists, clinicians and healthcare professionals but no PPI. ${ }^{11}$ Despite evidence emerging that patients and clinicians have different research priorities, ${ }^{12-16}$ 


\begin{tabular}{|c|c|c|}
\hline Domain & Emerging themes & Quotes \\
\hline Education & $\begin{array}{l}\text { Increase breast awareness } \\
\text { Use modern technologies and media } \\
\text { Age-relevant use of media/technologies } \\
\text { Appropriate level of information provision }\end{array}$ & $\begin{array}{l}\text { 'obviously I have heard about (screening) but I do not know much about ...' } \\
\text { 'everyone talks about a lump' } \\
\text { 'it wasn't a lump it was like a crease in the skin' } \\
\text { 'you can put symptoms....into Google' } \\
\text { 'the young girls .... have much bigger busts. They should be able to check' } \\
\text { 'it's got to be with the children, we've got to get in there early' } \\
\text { 'what age truly is too young? They all need to know about this' }\end{array}$ \\
\hline $\begin{array}{l}\text { Risk and } \\
\text { prevention }\end{array}$ & $\begin{array}{l}\text { Cause of breast cancer } \\
\text { Modifiable risk factors } \\
\text { Local (non-systemic) factors } \\
\text { (implants/underwires) } \\
\text { Role of diet and nutrition }\end{array}$ & $\begin{array}{l}\text { 'we were all completely different.... people say 'oh it's HRT'...(but) .....it doesn't seem to } \\
\text { have any rhyme or reason' } \\
\text { 'you get all this information and it's too much. Where do you draw the line!' } \\
\text { 'I've got concerns with the genetic side and family as well. I do have a mutation, it's a } \\
\text { random variant it's not a recognised one, it is connected to the BRCA genes' } \\
\text { 'you read conflicting things all the time' }\end{array}$ \\
\hline Screening & $\begin{array}{l}\text { Barriers to screening } \\
\text { 'Hard-to-reach' groups } \\
\text { Improved accuracy } \\
\text { Screening blood test } \\
\text { Improved understanding of genetics }\end{array}$ & $\begin{array}{l}\text { 'I did do years and years ago but then I just found it really inconvenient at work' } \\
\text { 'if people are not interested they are not interested' } \\
\text { 'if you had a pop up in the car park... if you made it fun' } \\
\text { 'I was in shock the first time but then when I knew what was coming I was a bit better } \\
\text { about it' } \\
\text { 'a lot of people do find a mammogram is so painful' } \\
\text { 'something might take the place of mammograms in the future, mightn't it' } \\
\text { 'perhaps in the future they might be able to determine by tests that we haven't even } \\
\text { thought about yet' } \\
\text { 'I think that's a lovely alternative, it doesn't hurt much, giving a blood sample' } \\
\text { 'I've got concerns ... I do have a mutation, it's a random variant it's not a recognised } \\
\text { one' } \\
\text { 'there are genetic things that we don't know' }\end{array}$ \\
\hline Diagnosis & $\begin{array}{l}\text { Information retention and decision-making } \\
\text { Impact of treatment delay } \\
\text { Expediency of test results }\end{array}$ & $\begin{array}{l}\text { 'I just did not hear a thing' } \\
\text { 'I drove through a red light .... I just could not concentrate' } \\
\text { 'you are just thinking 'am I going to die'. I found (reconstruction conversation) a lot to } \\
\text { take in' } \\
\text { 'I was not really quite prepared on how radical chemotherapy was' } \\
\text { 'it's just... waiting for the histology department ... to give out the results' }\end{array}$ \\
\hline
\end{tabular}

\begin{tabular}{|c|c|c|}
\hline Treatment & $\begin{array}{l}\text { Minimise re-operation } \\
\text { Maintaining arm mobility } \\
\text { Long-term reconstruction outcomes } \\
\text { Short-term and long-term side effect drugs }\end{array}$ & $\begin{array}{l}\text { 'if it doesn't work this time you'll have to have a mastectomy' } \\
\text { 'I was not really quite prepared on how radical chemotherapy was. Absolutely heart } \\
\text { breaking' } \\
\text { 'I did not realise the emotional effects of the side effects of treatment' } \\
\text { 'you need it (lymphoedema) dealing with.... you have suffered a lot with yours' } \\
\text { 'this other lady in work she wears (lymphoedema compression sleeve) all the time' } \\
\text { 'I have an issue with the tightness... of your muscle' } \\
\text { 'I think it's more the way it feels....it looks brilliant but it kind of, it's heavy and it's } \\
\text { different' } \\
\text { 'my granddaughter (was) sitting on my knee and her head bounces back on the false } \\
\text { one (implant reconstruction)... and she turns round, 'well I don't know what that was, } \\
\text { Grandma!' } \\
\text { 'mine (reconstruction) feel very alien to me' } \\
\text { 'I was waking up every hour ... absolutely drenched' } \\
\text { 'you just can't function with the tablets' }\end{array}$ \\
\hline $\begin{array}{l}\text { Psychological } \\
\text { aspects }\end{array}$ & $\begin{array}{l}\text { Cognitive techniques } \\
\text { Role of } \\
\text { Allied professionals } \\
\text { Lay support groups } \\
\text { Individualised (technologically age-relevant) } \\
\text { support }\end{array}$ & $\begin{array}{l}\text { 'It does not get out of your head completely no matter what. Where you have got your } \\
\text { nerves and fear and each time you go for a check' } \\
\text { 'it was the fear of telling people. You have actually got to vocalise it' } \\
\text { 'we all used to sort of like be in the waiting room discussing ours and yours and all this } \\
\text { sort of stuff' } \\
\text { 'a bit more use could be made of technology' } \\
\text { 'younger people, they'd be more used to receiving information in that way than perhaps } \\
\text { we are' }\end{array}$ \\
\hline
\end{tabular}

in 2018, the Association of Breast Surgery (ABS) in the UK published a complementary gap analysis that focused on surgical research themes, ${ }^{17}$ which included only one patient representative.

We set out to determine the research priorities of the public in breast cancer care, particularly focusing on early (non-metastatic) breast cancer. We aimed to identify whether the research priorities of patients and the public differed from those identified in the BCC gap analysis.

\section{PARTICIPANTS AND METHODS}

This study adopted an exploratory, qualitative approach, using 'listening events' (focus groups) to explore the identification of research themes by participants. Participants were sampled from attendees at four participating hospitals in the northwest of England, including patients and their family and friends. To capture public representatives naive to breast cancer treatment, participants were recruited by approaching staff at a local retail centre. In addition, a local breast cancer charity 
invited their supporters to participate in the study. Participants were over the age of 18, fluent English speakers and were recruited irrespective of previous participation in research, attitudes to research or perceived degree of articulacy. All interested potential participants were provided with an information sheet detailing the study and then contacted by the research team to confirm participation and listening group attendance details. Written consent, including to report anonymised quotations, was obtained at recruitment. We recruited from areas across the northwest of England that encompass diverse ethnic and socioeconomic groups in an attempt to ensure broad applicability of results. However, we did not record the sensitive data of participants' ethnicity or economic status. Recruitment was limited to women to allow and encourage an open discussion that may otherwise be inhibited by the presence of men.

Each participant attended one 'listening event'. Eight participants were invited to each listening group, with intentional over-recruitment in anticipation of nonattendance. Each listening event consisted of recruited participants, two researchers (GB, JRHe or RW) and an independent chair (PD). The independent chair was a trained research psychologist with experience in breast cancer research. The role of the independent chair was to moderate the discussion and provide help and support for the contributors. The role of the researchers was to provide fixed and predetermined prompting and to ensure that all aspects of the breast cancer pathway were discussed. Due to the large geographical area covered by the study, we opted to include participants in specific groups based on distance from venue to maximise recruitment and minimise inconvenience.

The listening events were of 2 hours duration, comprising a brief introduction, two $45 \mathrm{~min}$ free discussion periods and a summary at the end. It was emphasised to participants that they should freely converse about breast cancer, treatment and research. The researchers were primed to invite participants to discuss what they did and did not know about screening, diagnosis, treatment and survivorship relating to early (non-metastatic) breast cancer in women and to use semistructured questions where necessary to initiate discussion (eg, 'what do you know about...?'). We refer to survivorship as a concept of living with and beyond the diagnosis of cancer. The discussion was audio recorded and then transcribed before analysis. Listening events were conducted until no new discussion themes were raised, that is, saturation was reached.

\section{Patient and public involvement}

The study steering committee included two lay representatives from the outset. The lay representatives were involved in the design of the study and ethics application. They were also involved in manuscript drafting and revision, and approved the final version of the paper. We plan to disseminate the results to local patient groups that helped with recruitment.

\section{DATA ANALYSIS}

The data were analysed using NVivo software (V.11, QSR International) and the framework approach, ${ }^{18}$ a structured, systematic method of analysis that allows data to be explored across and between themes and participants yet retains flexibility such that the framework can be developed and refined as the data are analysed. The researchers (GB, RW and PD) independently coded transcripts of the listening events, and through a series of discussions, charting and re-examination of the data were able to jointly develop a framework that comprised the main themes arising from listening event discussions. These themes indicated the extent of participants' existing knowledge about breast cancer and its treatment and highlighted aspects about which they desired to know more. Further exploration and discussion of the data within each theme enabled the researchers (LB, JRHe, II) to identify gaps in research for which participants believed further research was warranted. We have not analysed the data based on the demographics of the individual participants (eg, if they were a patient or member of the public) as participants were not asked to identify themselves on speaking, as this may have interfered with conversation flow.

\section{RESULTS}

Four listening events were held, consisting of 6, 4, 5 and 12 participants, respectively. Two were held in Liverpool, one in South Manchester and one in Burnley, East Lancashire. All participants were women and included patients with breast cancer $(\mathrm{n}=16)$ and public representatives $(\mathrm{n}=11)$. The participants ages ranged from 26 to 75 (mean 55 years old) and for patients with breast cancer, the time since diagnosis ranged from 1 to 27 years (mean 7.6 years).

Listening events were held until no new discussion themes were raised, that is, saturation was reached. The themes identified by the researchers were grouped into six main domains: education, risk and prevention, screening, diagnosis, treatment and psychological aspects (table 1).

\section{EDUCATION}

The participants discussed the information available to women regarding the signs and symptoms of breast cancer and how this can be disseminated in a variety of forms. There was particular concern about educating younger women, and at what age and how to educate children. The role schools should have in delivering information on breast self-examination, signs, symptoms and modifiable risk factors and at what age was also considered.

It was highlighted that different generations access information differently, for example, using different media sources. Some felt that social media or the celebrity culture could be used to increase cancer awareness with one participant commenting 'I still think that we 
should be doing more about breast cancer awareness on the TV ads', another suggesting there could be an increase in breast cancer awareness via social media, and another suggesting lingerie departments could provide breast-awareness leaflets.

'How to examine' was an area focused on with, for example, one participant highlighting 'I didn't know a rash was a sign'. The possible variation in signs and symptoms according to age and how these may affect presentation to a healthcare professional was also discussed.

There were discussions around how to reach the "not interested', with acknowledgement of the importance of convenience in terms of access to information. There were concerns about how much information should be provided to the public, with participants commenting that the information given at times was 'too much' and stated several times a feeling of 'information overload'.

\section{RISK AND PREVENTION}

Discussions focused on the need for more clarity about modifiable risk factors, for example, the impact of the contraceptive pill. There was also discussion about the impact of underwired bras, reflecting the impact of nonevidence reporting in the media and raising the issue of how this effect can be mitigated. It was observed that some people felt they had a 'false sense of security... when you're healthy', with one stating 'I'm size 10 and I eat really healthily etc. there's no way I could ever have breast cancer'.

Equally, it was highlighted that there was a need for a better understanding of the causes of breast cancer, as exemplified by participants saying 'I don't understand why when I had my breast cancer' and '.... what causes it because I thought I led a very healthy life'. There was specific discussion in one group around breast augmentation and the impact of this on development of breast cancer or how it may hinder the diagnosis of breast cancer through altered symptom presentation or reduced screening sensitivity.

The role of diet in breast cancer, particularly in terms of breast cancer recurrence, was also a point of discussion, it is being highlighted that 'you don't know what is fact and what is fiction'.

\section{SCREENING}

The participants discussed the potential barriers to universal attendance at breast screening. These included personal or anecdotal experience of screening, lack of education on the benefits of screening and the inconvenience of attending screening at a fixed time and place. One participant suggested 'a mammogram wagon like the .... blood donors .... where they go around to organisations'.

Most found the screening process a 'large inconvenience' especially fitting this around work or childcare. It was felt that this may reflect a lack of emphasis on the importance of the screening process or it may simply be a practical inconvenience in location, timing or inflexibility of the screening programme. One had commented that 'I do not go to screening, not that I do not want to go to screening but because I never find time'.

There was a discussion around the patient experience in terms of anxiety, particularly following a negative experience, for example, 'I can still put myself straight back in that room now'. The discomfort of mammograms was acknowledged, 'I do not know what really goes on... but it just sounds awful'; 'I think a lot of people do find a mammogram is so painful, it puts them off'. There was also discussion about screening age and the lack of understanding behind why ages are targeted. The methods of delivering normal result were considered, with one remarking 'I wouldn't have minded getting a text to say, you know, the results'.

There was a discussion about public awareness of the need for screening, with one participant highlighting 'if you think .... you can find a lump yourself and screening is just to catch the leftovers you're not going to go'.

It was also highlighted that there was a need to do research into identifying which groups are not attending screening, or which groups present late with breast cancer and explore the reasons behind this. It was recognised that there was a need to improve engagement with screening by 'hard to reach' groups such as some ethnic minorities.

The limitations of breast screening were discussed, for example, 'mammograms actually don't show all forms of cancers...... mammograms aren't wonderful' and the desirability of other potential forms of screening such as blood tests. Also fears associated with the harm of screening were debated including concerns that 'squashing of the breast is actually going to damage it and may cause cancer' and that 'biopsy .... may carry it.... off all round your body'.

There was debate about whether genetic screening should be available to all women regardless of risk stratification, at what age it should be offered and wishes that 'a new universal (genetic) test' could be created. The need for clarity about the implications of some gene variants (variant of uncertain significance) was also commented on.

\section{DIAGNOSIS}

The quantity of information delivered at the time of diagnosis was a topic of debate. There were queries raised about possible links between disease, prognosis and retention of information, which in part reflects the more complicated treatment pathway that needs to be discussed in poorer prognosis disease. There were discussions about how retention of information could be improved, with one participant commenting, 'it is not that you don't listen, you cannot take it in'.

There were concerns raised about the impact of waiting for test results and treatment, both in terms of anxiety and in terms of potential disease progression. However much of these concerns focused on waiting for results, for example, 'I think a lot of time is spent waiting for histology results' and 'my pathology held things up for quite a long time'. The role of staging imaging and when it should be performed or 
omitted was also discussed, not only just in terms of accurate disease staging but also in terms of the potential anxiety or reassurance provided by a scan.

\section{TREATMENT}

The participants discussed the side effects of surgical and adjuvant treatments including chemotherapy, radiotherapy and endocrine therapy.

\section{Surgery}

The majority of responders had undergone surgical intervention and axillary treatment. The problems of lymphoedema were discussed, and the suffering was associated with it. It was questioned why some patients have to have the treatment they do, and why side effects vary, with one asking, 'Why do some people react to the treatment they have?'.

The issue of reoperation and completion mastectomy following failure to clear margins was discussed, such as ' ...if there was some research... which would identify the margins more clearly that would save a lot of ...(re-) excisions'.

The need for ongoing physiotherapy support to maximise and maintain mobility and function was highlighted, with concerns raised that this treatment was not being delivered sufficiently effectively.

Participants were keen to be given realistic and honest explanations of their likely surgical outcome, including complications. There were discussions around understanding long-term outcomes of the different forms of reconstruction when choosing what to have, for example, the differences in feel of different types of reconstruction; 'mine feel very alien to me...whereas yours is your own tissue'.

\section{Systemic therapy}

The effect of different types of endocrine therapy, including different brands, on side effect profiles, particularly musculoskeletal, hot flushes and mood, was a major point of focus, for example, 'I could hardly walk, my husband and I were looking at wheelchairs, I was in so much pain' and 'Tamoxifen actually destroyed my mood ....I stopped taking it'. Concerns were raised as to how this impacted compliance, and this was recognised as an important area for research. Some participants also referred to a lack of forewarning as to the impact of treatment: 'I was not really quite prepared on how radical chemotherapy was. Absolutely heart breaking' and 'I did not realise the emotional effects of the side effects of treatment' and 'I looked like an alien ... that is the hardest thing to get around...the surgery is a piece of cake compared with dealing with that'.

\section{PSYCHOLOGICAL ASPECTS}

This domain was the most extensively discussed. The psychological impact of breast cancer on patient participants and those around them was an emotive subject. The feeling of 'loneliness' and the 'fear of death' were discussed. There was extensive conversation around the role of psychological techniques to help with anxiety, particularly around the fear of recurrence. The importance of the role of the breast care nurse was highlighted. The potential need for ongoing support after discharge from routine clinical follow-up was considered.

The effects of patient with breast cancer groups on well-being and empowerment and how this could be maximised were also debated. The impact of a breast cancer diagnosis on family and friends, its potential to change family dynamics and how this can be minimised was an important discussion area. It was also highlighted that younger generations may be more comfortable with receiving information and communications via devices rather than face-to-face or hard copy formats, and that management of long-term psychological health may have to be tailored to different generations.

\section{COMPARISON TO PUBLISHED GAP ANALYSES}

There were several themes identified in this current gap analysis that were not reported in either the BCC gap analysis ${ }^{11}$ or the ABS gap analysis ${ }^{17}$ (table 2 ).

\section{DISCUSSION}

Despite evidence that patients and members of the public have different research priorities to healthcare professionals, ${ }^{13-16} 1920$ the two published gap analyses of breast cancer research priorities had minimal input from the public. ${ }^{117}$ We set out to identify the research priorities of the public and compare them to those of clinicians and scientists working in the field of breast cancer.

In the listening groups held in this study, there was clear emphasis on the need for improved methods of dissemination of information, at all stages of the breast cancer pathway from breast awareness and screening, to survivorship. There was a strong emphasis on education about the signs and symptoms of breast cancer and how these may affect presentation to healthcare services. Modification of the current mammographic screening programme was also a prominent theme, with awareness that screening uptake, or improved methods of screening, were issues that needed research.

Although a large focus of the conversations was around service improvement, it was recognised that research into technologies could improve the patient pathway. This was exemplified by discussion around the time for pathology assessment and the need for reoperations because of involved surgical excision margins.

Our study particularly demonstrated a strong focus by participants on quality-of-life-related issues, with side effects of surgery, endocrine therapy and chemotherapy being a focus of discussion. The psychological impact of a cancer diagnosis and survivorship featured strongly as patients felt that these were under-researched, and areas where improvements could be made. A study by Corner et al investigating research priorities also found that quality of life issues and cancer risk factors were the two highest ranked topics identified by patients with cancer. ${ }^{21}$ That study involved asking the patients to vote for their top three research priorities. It is 
Table 2 Comparison of topics identified by this current PPP study, the 2013 BCC gap analysis ${ }^{11}$ and the 2018 ABS gap analysis ${ }^{17}$

\begin{tabular}{|c|c|c|c|}
\hline & $\begin{array}{l}\text { PPP } \\
\text { study }\end{array}$ & $\begin{array}{l}\text { BCC } \\
\text { analysis }\end{array}$ & $\begin{array}{l}\text { ABS } \\
\text { analysis }\end{array}$ \\
\hline $\begin{array}{l}\text { Information on symptoms, } \\
\text { diagnosis and treatment }\end{array}$ & $\sqrt{ }$ & & \\
\hline Self-examination & $\sqrt{ }$ & & \\
\hline Risk factors & $\sqrt{ }$ & $\sqrt{ }$ & \\
\hline Prevention & $\sqrt{ }$ & $\sqrt{ }$ & \\
\hline Screening & $\sqrt{ }$ & $\sqrt{ }$ & \\
\hline $\begin{array}{l}\text { Symptomatic assessment and } \\
\text { diagnosis }\end{array}$ & $\sqrt{ }$ & & $\sqrt{ }$ \\
\hline Staging and monitoring disease & $\sqrt{ }$ & & $\sqrt{ }$ \\
\hline Neoadjuvant treatment & & & $\sqrt{ }$ \\
\hline $\begin{array}{l}\text { Breast conserving surgery } \\
\text { (including re-excision) }\end{array}$ & $\sqrt{ }$ & & $\sqrt{ }$ \\
\hline Management of axilla & & & $\sqrt{ }$ \\
\hline Reconstruction & $\sqrt{ }$ & & $\sqrt{ }$ \\
\hline 'Personalised' treatment & & $\sqrt{ }$ & $\sqrt{ }$ \\
\hline Side effects of treatment & $\sqrt{ }$ & $\sqrt{ }$ & \\
\hline Treatment markers & & $\sqrt{ }$ & $\sqrt{ }$ \\
\hline Imaging biomarkers & & $\sqrt{ }$ & $\sqrt{ }$ \\
\hline Metastatic disease & & & $\sqrt{ }$ \\
\hline $\begin{array}{l}\text { Over-diagnosis and over- } \\
\text { treatment }\end{array}$ & & $\sqrt{ }$ & $\sqrt{ }$ \\
\hline B3 lesions/DCIS & & & $\sqrt{ }$ \\
\hline $\begin{array}{l}\text { Outcomes (clinical, patient, } \\
\text { cosmetic) }\end{array}$ & $\sqrt{ }$ & & $\sqrt{ }$ \\
\hline Risk reducing surgery & & & $\sqrt{ }$ \\
\hline $\begin{array}{l}\text { Psychological impact of } \\
\text { diagnosis }\end{array}$ & $\sqrt{ }$ & $\sqrt{ }$ & \\
\hline Living after/with breast cancer & $\sqrt{ }$ & $\sqrt{ }$ & \\
\hline (Epi) genetic changes in cancer & $\sqrt{ }$ & $\sqrt{ }$ & \\
\hline $\begin{array}{l}\text { Cancer subtypes and patient } \\
\text { subgroups }\end{array}$ & & $\sqrt{ }$ & $\sqrt{ }$ \\
\hline $\begin{array}{l}\text { Molecular mechanisms of } \\
\text { cancer development }\end{array}$ & $\sqrt{ }$ & $\sqrt{ }$ & \\
\hline Translational research & & $\sqrt{ }$ & $\sqrt{ }$ \\
\hline
\end{tabular}

ABS, Association of Surgery; BCC, Breast Cancer Campaign;

DCIS, ductal carcinoma in situ; PPP, patient and public priorities.

interesting to note that, contrary to our findings, the organisation of services did not rank highly among patients in the Corner study.

The BCC analysis comprised 100 scientists and clinicians who determined the top 10 clinical research gaps and translational priorities in breast cancer. Our results predominantly share focus with two of the BCC priorities (lifestyle changes and living with and managing breast cancer and its treatment). It is not surprising that the participants in our study did not delve into the molecular basis of breast cancer and translational research but did discuss 'why does breast cancer happen' and the implications of genetics in breast cancer. Perhaps more surprising, they did not discuss the impact of different treatment modalities on survival. There was less cross over between our results and those of the ABS surgical analysis, with the main topics in common being assessment, diagnosis, staging and monitoring of disease, although surgical outcomes were also touched on. Interestingly, our participants did not discuss personalised screening and treatment or address the issue of overdiagnosis and overtreatment despite expressing strong desire for more research into early detection and possible population genetic screening. As we did not have specific questions that we asked participants, the topics we identified were necessarily broad. Nevertheless, it is interesting that our participants raised topics that were not obviously covered by the two previous studies.

One bias of our study is that patients and members of the public have little medical knowledge and therefore would be expected to have different priorities to breast cancer scientists who took part in the BCC gap analysis as they may be less likely to consider the molecular, genetic or scientific aspects of breast cancer or have a deep understanding of the possibilities of clinical trials when assessing what their research priorities are. Indeed, much of what is in the BCC gap analysis will not be accessible information to patients and the public. This study does however emphasise that patients have a voice and to establish research priorities we need to have a pool of patients with research expertise or experience to guide funders and researchers. Although we conducted our focus groups in a variety of settings across the northwest of England, our data may not be directly translatable to other populations that may differ in their socioeconomic and ethnic composition. In addition, volunteer participants were asked to speak openly in the events which may have biased self-selection towards or against certain demographics.

The participants in our study included public representatives and patients with breast cancer. This allowed a wide-ranging discussion that was not solely from a patient's perspective. The resultant topics encompassed the totality of a woman's possible encounters with breast services starting from self-examination through screening to possible diagnosis of breast cancer and its management to support after discharge from follow-up. We did not, however, consider advanced disease in this study, likely due to no participants being at this stage in the disease. One of the unexpected findings of our study is the impact of the technicalities of service provision on patient well-being, for example, the amount of time spent at the one-stop clinic, the length of time waiting for a pathology or radiology result. Although this is more of a service improvement rather than a primary research area, it is clear that relatively minor changes to the patient's journey may have a substantial positive impact on their well-being.

This study highlights the importance of including patients and the public when setting research priorities. The results of this study provide an insight into lay priorities for breast cancer research and should be used to guide investigators when planning future studies. 
Acknowledgements The authors are grateful to Dr Gavin Daker-White for the invaluable assistance in the setup and running of the study.

Collaborators The Northwest Breast Research Collaboration: Laura Ballance, George Boundouki, Rajiv Dave, James R Harvey, Julia R Henderson, Ibrahim Ibrahim, Mustafa Khanbhai, Cliona C Kirwan, Ashley Topps, Kate Williams, Rebecca L Wilson

Contributors GB, RW, PD, JHe, LB, JW, VA, JHa and CCK contributed to the planning of the study. Data collection was performed by GB, RW, PD and JHe. Data analysis was performed by GB, RW, PD, JHe, LB, II and CCK. GB, RW, PD, LB, JHa and CCK were involved in the drafting and revision of the manuscript. All authors approved the final version of the manuscript. The corresponding author attests that all listed authors meet authorship criteria and that no others meeting the criteria have been omitted. CCK is the study guarantor.

Funding The study was funded by a grant from the Association of Breast Surgery.

Competing interests All authors have completed the ICMJE uniform disclosure form at http://www.icmje.org/coi_disclosure.pdf and declare: grant support from the Association of Breast Surgery for the submitted work; no financial relationships with any organisations that might have an interest in the submitted work in the previous three years, no other relationships or activities that could appear to have influenced the submitted work.

Patient consent for publication Not required.

Ethics approval The study was approved by the NHS Health Research Authority, London-Central Research Ethics Committee (16/L0/0162).

Provenance and peer review Not commissioned; externally peer reviewed.

Data availability statement No additional data available.

Open access This is an open access article distributed in accordance with the Creative Commons Attribution Non Commercial (CC BY-NC 4.0) license, which permits others to distribute, remix, adapt, build upon this work non-commercially, and license their derivative works on different terms, provided the original work is properly cited, appropriate credit is given, any changes made indicated, and the use is non-commercial. See: http://creativecommons.org/licenses/by-nc/4.0/.

\section{ORCID iDs}

George Boundouki http://orcid.org/0000-0003-1020-5029

Cliona Clare Kirwan http://orcid.org/0000-0002-1725-4790

\section{REFERENCES}

1 Cancer registration statistics, England. Office for national statistics, 2016.

2 Cancer Incidence in Scotland. Information services division, NHS Scotland, 2016.

3 Bray F, Ferlay J, Soerjomataram I, et al. Global cancer statistics 2018: GLOBOCAN estimates of incidence and mortality worldwide for 36 cancers in 185 countries. CA Cancer J Clin 2018;68:394-424.

4 Carioli G, Malvezzi M, Rodriguez T, et al. Trends and predictions to 2020 in breast cancer mortality in Europe. Breast 2017;36:89-95.
5 NCRI. Breast cancer clinical studies group annual report, 2017: 2016-7.

6 Staley K, Hanley B. Scoping research priority setting (and the presence of PPI in priority setting) with UK clinical research organisations and funders. secondary scoping research priority setting (and the presence of PPI in priority setting) with UK clinical research organisations and funders, 2008. Available: http://www. twocanassociates.co.uk/perch/resources/files/TwoCan\%20JLA\% 20report\%20March\%2009_with\%20appendices.pdf

7 Nasser M, Welch V, Tugwell P, et al. Ensuring relevance for Cochrane reviews: evaluating processes and methods for prioritizing topics for Cochrane reviews. J Clin Epidemiol 2013;66:474-82.

8 Hubbard G, Kidd L, Donaghy E. Involving people affected by cancer in research: a review of literature. Eur $J$ Cancer Care 2008;17:233-44.

9 Entwistle VA, Renfrew MJ, Yearley S, et al. Lay perspectives: advantages for health research. BMJ 1998;316:463-6.

10 NIHR. INVOLVE. Secondary INVOLVE. Available: http://www.invo.org. uk/

11 Eccles SA, Aboagye EO, Ali S, et al. Critical research gaps and translational priorities for the successful prevention and treatment of breast cancer. Breast Cancer Res 2013;15:R92.

12 Grant-Pearce C, Miles I, Hills P. Mismatches in priorities for health research between professionals and consumers : a report to the standing advisory group on consumer involvement in NHS R and D Programme: PREST, 1998.

13 Bethell J, Pringle D, Chambers LW, et al. Patient and public involvement in identifying dementia research priorities. J Am Geriatr Soc 2018;66:1608-12.

14 Morris RL, Stocks SJ, Alam R, et al. Identifying primary care patient safety research priorities in the UK: a James Lind alliance priority setting partnership. BMJ Open 2018;8:e020870.

15 Manikam L, Shah R, Reed K, et al. Using a co-production prioritization exercise involving South Asian children, young people and their families to identify health priorities requiring further research and public awareness. Health Expect 2017;20:852-61.

16 Cox A, Arber A, Gallagher A, et al. Establishing priorities for oncology nursing research: nurse and patient collaboration. Oncol Nurs Forum 2017;44:192-203.

17 Cutress RI, Mclntosh SA, Potter S, et al. Opportunities and priorities for breast surgical research. Lancet Oncol 2018;19:e521-33.

18 Ritchie J, Spencer L, O'Connor W. Carrying out qualitative analysis. In: Ritchie J, Lewis J, eds. Qualitative research practice: a guide for social science students and researchers. London: SAGE, 2003: 219-62.

19 Kelly S, Lafortune L, Hart N, et al. Dementia priority setting partnership with the James Lind alliance: using patient and public involvement and the evidence base to inform the research agenda. Age Ageing 2015;44:985-93.

20 Manns B, Hemmelgarn B, Lillie E, et al. Setting research priorities for patients on or nearing dialysis. Clin J Am Soc Nephrol 2014;9:1813-21.

21 Corner J, Wright D, Hopkinson J, et al. The research priorities of patients attending UK cancer treatment centres: findings from a modified nominal group study. Br J Cancer 2007;96:875-81. 